\title{
Flexible composite via rapid titania coating by microwave-assisted hydrothermal synthesis
}

\author{
RICARDO MARQUES E SILVA ${ }^{1}$, ANDERSON THESING ${ }^{2}$, VINICIUS GONÇALVES DEON ${ }^{1}$, \\ ALICE GONÇALVES OSÓRIO ${ }^{1}$, BRUNO DA SILVEIRA NOREMBERG ${ }^{1}$, \\ NATÁLIA HADLER MARINS ${ }^{1}$, MARCELO ORNAGHI ORLANDI ${ }^{3}$, \\ FABIANA VILLELA DA MOTTA ${ }^{4}$, RUBENS MARIBONDO DO NASCIMENTO ${ }^{4}$ and \\ NEFTALI LENIN VILLARREAL CARREÑO ${ }^{1, *}$ \\ ${ }^{1}$ Graduate Program in Materials Science and Engineering, CDTec, Federal University of Pelotas, Gomes Carneiro 1, \\ Pelotas, RS 96010-610, Brazil \\ ${ }^{2}$ Materials Science Postgraduate Program (PGCIMAT), Federal University of Rio Grande do Sul, Porto Alegre, RS \\ 91501-970, Brazil \\ ${ }^{3}$ Department of Physical Chemistry, Institute of Chemistry, Paulista State University (UNESP), Araraquara, \\ SP 14800-900, Brazil \\ ${ }^{4}$ Department of Materials Engineering, Technology Center, Federal University of Rio Grande do Norte, Natal, \\ RN 59078-970, Brazil \\ *Author for correspondence (neftali@ufpel.edu.br)
}

MS received 29 March 2016; accepted 7 August 2016; published online 9 June 2017

\begin{abstract}
The aim of this work was to prepare a flexible nanocomposite from ultra-fine titanium oxide $\left(\mathrm{TiO}_{2}\right)$ growth on carbon fibre via microwave-assisted hydrothermal synthesis (MHS) and to evaluate its photocatalytic properties. The $\mathrm{TiO}_{2}$ nanoparticles were directly grown on the carbon fibre (CF). Thus, a study comparing the conventional titania coating $v s$. the MHS were performed. The significant layer interaction as a function of the coating method on the visible and dark dye photodegradation performance was observed. Techniques such as X-ray diffraction, electron microscopy (field-emission scanning electron microscope (FESEM)), Raman spectroscopy, among others were used aiming to characterize the different route samples. This study reports a reproducible and single method to manufacture of nanocomposites through the growth of $\mathrm{TiO}_{2}$ nanoparticle on CF by MHS that allow controlling the thickness layer. Similar procedure of synthesized nanocomposite could be applied in different chemical compositions to advanced applications, based on the electrochemical nanostructure.
\end{abstract}

Keywords. Nanoparticles; titanium dioxide; microwave-assisted hydrothermal synthesis; carbon fibre.

\section{Introduction}

Several materials and methods have been investigated for solution coating of semiconductors that offer excellent potential for achieving low-cost manufacturing and flexible electronic devices. An alternative method is to use semiconductor materials such as titanium oxide $\left(\mathrm{TiO}_{2}\right)$, but there are problems like low efficiency during processing as well as the immobilization of $\mathrm{TiO}_{2}$ particles in porous matrices (flexible holders). Among the most commonly used matrices, the carbon fibres (CF) present better properties for this purpose, such as a good adsorption capacity, dark colour, and a uniform pore structure $[1,2]$. They are also in the form of felt or tissue, which is preferable for handling when compared with the granular holders. Moreover, the synergistic effect between $\mathrm{TiO}_{2}$ and carbon can greatly retard the recombination of photo-induced electrons and holes, leading to improved electrochemical performance of $\mathrm{TiO}_{2}$, as well as the possibility of forming flexible composites. A recent study showed that the $\mathrm{CF}$ surface can be treated with nitric acid $\left(\mathrm{HNO}_{3}\right)$ to change its topographies and obtain better performance when impregnated with nanoparticles, which is evidenced by the increased surface roughness caused by etching, thereby making the impregnation easier [2]. Therefore, $\mathrm{HNO}_{3}$-treated $\mathrm{CF}$ was selected as the matrix for the loading of $\mathrm{TiO}_{2}$ by two different methods in this study. The first technique immersed the $\mathrm{HNO}_{3}$-treated $\mathrm{CF}$ in an impregnation solution containing conventional $\mathrm{TiO}_{2}$ nanoparticles. The second method was via microwave-assisted hydrothermal synthesis (MHS) that could allow the synthesis of different morphologies of the $\mathrm{TiO}_{2}$ nanoparticles in a short period of time, with controlled particle thickness and employing a clean process. Besides, this technique enables the growth of other nanoparticles, such as stabilized lead zirconate titanate (PZT), which exhibits piezoelectric properties. More nanoparticles were adsorbed via MHS on the CF surface, with fewer crystal defects and well-defined morphology and without the necessity of further treatments [3-6]. The coating fibre 
allows the obtainment of a versatile nanocomposite with properties desirable to structural, chemical and physical applications.

\section{Experimental}

\subsection{Materials and methods}

Analytical grade reagents were used without further purification. The surface treatment of the $\mathrm{CF}$ was performed with concentrated $\mathrm{HNO}_{3}$. The fibre samples (dimensions of $30 \times 30$ mm) were immersed in $\mathrm{HNO}_{3}$ solution at $90^{\circ} \mathrm{C}$ for $30 \mathrm{~min}$ in order to increase the surface area and facilitate the impregnation of nanoparticles by creating surface defects.

A fibre sample that was not subjected to treatment $(0 \mathrm{~min})$ was used as a standard. After the treatment, the CF samples were washed in distilled water at $100^{\circ} \mathrm{C}$ and then oven dried at $50^{\circ} \mathrm{C}$ for $2 \mathrm{~h}$ (treated). After, $0.078 \mathrm{~g}$ of conventional P25 $\mathrm{TiO}_{2}$ were dispersed in $100 \mathrm{ml}$ of distilled water to form an aqueous solution with a concentration of $1 \mathrm{mM}$. This solution was dispersed for 15 min by a sonication probe. The CF samples treated were immersed in this solution for $24 \mathrm{~h}$ in order to impregnate the $\mathrm{CF}$ surface with conventional P25 $\mathrm{TiO}_{2}$ nanoparticles. Henceforth, the samples are referred to as $\mathrm{CF}$ + P25 or conventional composite.

The titanium glycolate used to prepare the $\mathrm{CF}$ and $\mathrm{TiO}_{2}-$ MHS nanocomposites by MHS was prepared by following a method reported by Wang et al [7]. Later, the samples were stored for further use. Both $\mathrm{TiO}_{2}-\mathrm{MHS}$ powder and the $\mathrm{CF}$ and $\mathrm{TiO}_{2}-\mathrm{MHS}$ nanocomposites were synthesized inside a polytetrafluoroethylene (PTFE) vessel in a temperaturecontrolled microwave oven (MEF41, Electrolux, Brazil). For synthesis of the pure $\mathrm{TiO}_{2}$ powder, $0.30 \mathrm{~g}$ of the previously prepared titanium glycolate were dispersed in $50 \mathrm{ml}$ of absolute ethanol (A1084.01.BJ, Synth, Brazil), using a sonication probe (Disruptor, Unique, Brazil) for $20 \mathrm{~min}$. Subsequently, $50 \mathrm{ml}$ of distilled water was added to the solution and sonicated for $2 \mathrm{~min}$. The final dispersion was placed in the PTFE vessel and heated at $150^{\circ} \mathrm{C}$ for $20 \mathrm{~min}$. After cooling up to room temperature $\left(\sim 24^{\circ} \mathrm{C}\right)$, the white precipitate was collected and washed three times with absolute ethanol. The washed precipitate was dried in an oven (A5SE, DeLeo, Brazil) with no air circulation for $12 \mathrm{~h}$. Hence, the material is referred to as $\mathrm{TiO}_{2}-\mathrm{MHS}$. The synthesis of the $\mathrm{CF}-\mathrm{TiO}_{2}$ nanocomposite followed the same procedure and conditions used for the synthesis of the pure $\mathrm{TiO}_{2}$ powder, differing only by the addition of the CF sample (dimensions of $30 \times 30 \mathrm{~mm}$ ) to the titanium glycolate dispersion. The resulting nanocomposite was washed with distilled water several times until no more particles could be rinsed from the fibre, followed by drying in an oven for $12 \mathrm{~h}$. Henceforth, the $\mathrm{CF}-\mathrm{TiO}_{2}$ via MHS nanocomposite is referred to as $\mathrm{CF}$ and $\mathrm{TiO}_{2}-\mathrm{MHS}$. An alternative and promising idea using the same technique, can be the growth of PZT by MHS method. In order to produce these composites $3.31 \mathrm{~g}$ of lead nitrate (Vetec, Brazil), $0.884 \mathrm{~g}$ of zirconium nitrate (Vetec, Brazil), and $1.39 \mathrm{~g}$ of titanium isopropoxide (Sigma Aldrich, USA) were dispersed in $40 \mathrm{ml}$ of distilled water. Then, $11.20 \mathrm{~g}$ of potassium hydroxide (Synth, Brazil) was gradually added to this solution. Later, the material was placed in the microwave oven at $160^{\circ} \mathrm{C}$ for $2 \mathrm{~h}$.

\subsection{Characterization}

The crystalline structure of the conventional P25 $\mathrm{TiO}_{2}$, $\mathrm{TiO}_{2}-\mathrm{MHS}$ and PZT powders were characterized by powder X-ray diffraction (XRD; 6000, Shimadzu, Japan), using a monochromator with $\mathrm{CuK}_{\alpha}$ radiation $(\lambda=1.5418 \AA)$ in the scan range of $10-80^{\circ} \mathrm{C}$. The Raman spectra were obtained with a Raman spectrometer (inViaT640001, Renishaw, USA) equipped with triple monochromator and coupled to a chargecoupled device detector. An argon laser with a wavelength of $532 \mathrm{~nm}$ was used as the excitation source. The spectra were obtained by observing the radiation scattered at $180^{\circ} \mathrm{C}$ to the incident radiation ('back scattering') with a $\times 50$ lens. For spectra acquisition, accumulations were not used. The determination of the surface area of the nanoparticles was performed using multi-molecular adsorption theory and measuring the physical adsorption of $\mathrm{N}_{2}$ gas at $77 \mathrm{~K}$. The adsorption and desorption isotherms for subsequent determination of the specific surface area $\left(S_{\mathrm{BET}}\right)$ of the materials were measured with a surface area analyzer (BELSORP-mini, BEL Japan Inc., Japan) by Brunauer-Emmett-Teller method. Thus, $0.246 \mathrm{~g}$ of each sample was dried at $120^{\circ} \mathrm{C}$ under an $\mathrm{N}_{2}$ stream for $3 \mathrm{~h}$. The size and morphology of the nanocomposites were analysed using a field-emission scanning electron microscope (FESEM; JSM-7500F, JEOL, Japan). An energydispersive X-ray spectrometer (720, Shimadzu, Japan) was used to quantify the presence of $\mathrm{TiO}_{2}$. Band gap calculation and ultraviolet-visible (UV-vis) spectroscopy (Cary 100 UV-visible spectrophotometer, Agilent, USA) were used to determine the photocatalytic properties as well.

The interaction between the coating and the fibre was monitored by layer dye photodegradation experiments, $50 \mathrm{ml}$ of an aqueous solution of rhodamine $\mathrm{B}(\mathrm{RhB})$ with the initial concentration of $2 \times 10^{-7} \mathrm{M}$ was used as a model to evaluate the photocatalytic activity of the nanocomposites. Samples of nanocomposites $(30 \times 30 \mathrm{~mm})$ were placed symmetrically in a reaction cell and exposed to a $160 \mathrm{~W}$ mercury lamp $(\lambda>380$ $\mathrm{nm}$ ) that was fixed along the cell axis. The distance between the solution and the lamp was kept constant at $100 \mathrm{~mm}$. The photocatalytic reaction was monitored by sampling $1.5 \mathrm{ml}$ of each processed solution for 30 min to measure the absorbance at $\lambda=553 \mathrm{~nm}$ using a UV-vis spectrophotometer.

\section{Results and discussion}

\subsection{Nanocomposite characterization}

The XRD patterns of conventional P25 $\mathrm{TiO}_{2}, \mathrm{TiO}_{2}-\mathrm{MHS}$ and PZT are showed in figure 1 as well as the identification 

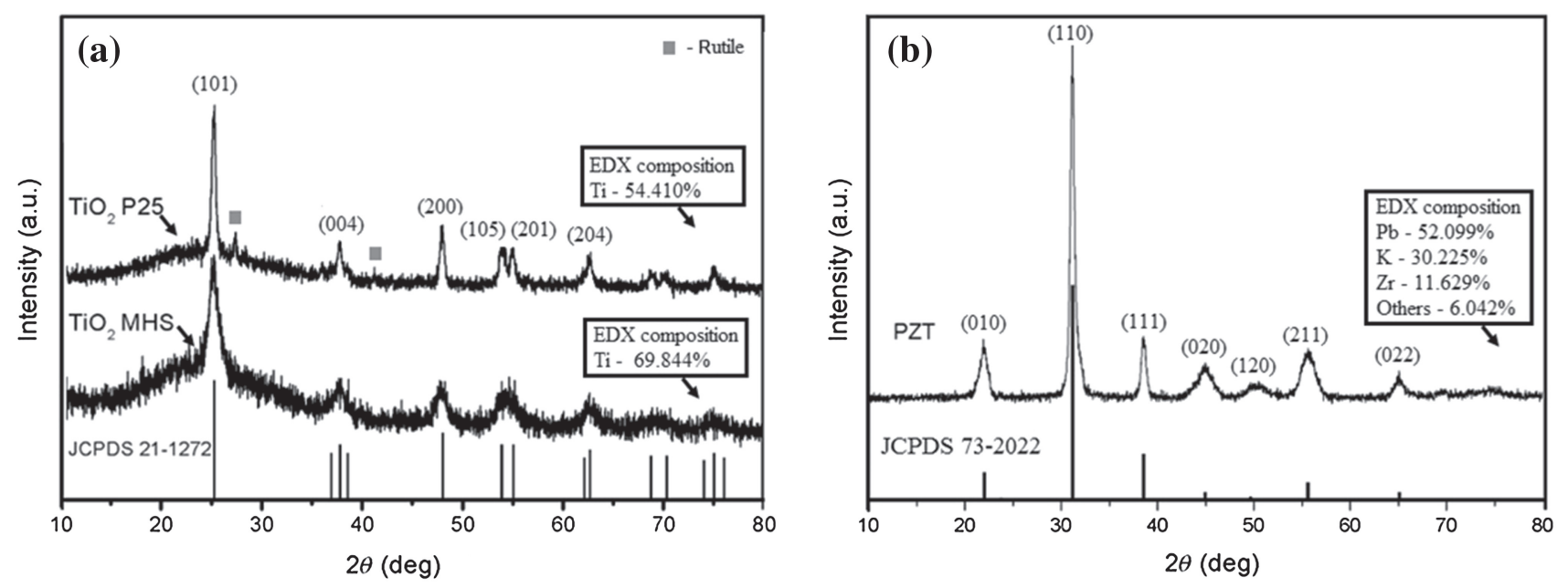

Figure 1. XRD patterns of Standard and EDX of (a) $\mathrm{TiO}_{2} \mathrm{P} 25$ and $\mathrm{TiO}_{2}-\mathrm{MHS}$ and (b) PZT.

of chemical elements on the surface by X-ray spectrometer, which showed the presence of a larger amount of titanium in the sample prepared via MHS when compared to the conventional method. For XRD, as expected, the P25 $\mathrm{TiO}_{2}$ has anatase and trace of rutile phases. The diffraction peaks of $\mathrm{TiO}_{2}-\mathrm{MHS}$ sample can be indexed to an anatase-type structure, according to its JCPDS card, as well as PZT sample and its respective pattern card. The peaks of the $\mathrm{TiO}_{2}-\mathrm{MHS}$ sample are broader and have lower intensities, indicating that the crystallinity was lower and the particle size was smaller than $\mathrm{P} 25 \mathrm{TiO}_{2}$. Regarding the peak characteristic of plane observed in $\mathrm{TiO}_{2}-\mathrm{MHS}$ sample, which shows broader and lower peak intensities that could be peaks superimposed and eventually the presence of rutile phase and its peak characteristic. In addition, the carbon XRD patterns can interfere with $\mathrm{TiO}_{2}-\mathrm{MHS}$ phase $[8,9]$. The patterns of the nanocomposites are inconclusive owing to the overlapping peaks of $\mathrm{CF}$ and $\mathrm{TiO}_{2}$ fine particles, as functions of MHS method apply here.

Figure 2 shows the Raman peaks near 148, 400, 518 and $640 \mathrm{~cm}^{-1}$ that are associated with the anatase $\mathrm{TiO}_{2}$ mode $[8$, $10,11]$. Two other low-intensity broadband peaks are located at $\sim 1355$ and $\sim 1582 \mathrm{~cm}^{-1}$, which correspond to the D-band (induced by defects) and G-band (graphite mode) of carbon, respectively $[12,13]$.

The peaks in the Raman spectrum of the $\mathrm{CF}$ and $\mathrm{TiO}_{2}-\mathrm{MHS}$ sample have higher intensities than those in the spectrum of the $\mathrm{CF}+\mathrm{P} 25$ sample (figure 2), probably due to higher coating homogeneity as a result of the MHS employed.

On the basis of the results obtained from the Raman spectra, it is possible to calculate the ratio of the D- and G-band intensities $\left(I_{\mathrm{D}}\right.$ and $\left.I_{\mathrm{G}}\right)$ to evaluate the extent of disorder in the CF that originate from defects associated with vacancies, grain boundaries and amorphous carbons. The calculated $I_{\mathrm{D}}$ and $I_{\mathrm{G}}$ ratios showed little change among the samples with a value of 0.8565 for $\mathrm{HNO}_{3}$-treated $\mathrm{CF}, 0.8512$ for $\mathrm{CF}+\mathrm{P} 25$ and 0.8578 for $\mathrm{CF}$ and $\mathrm{TiO}_{2}-\mathrm{MHS}$. These values showed few variations among themselves, indicating the absence of phase shift,

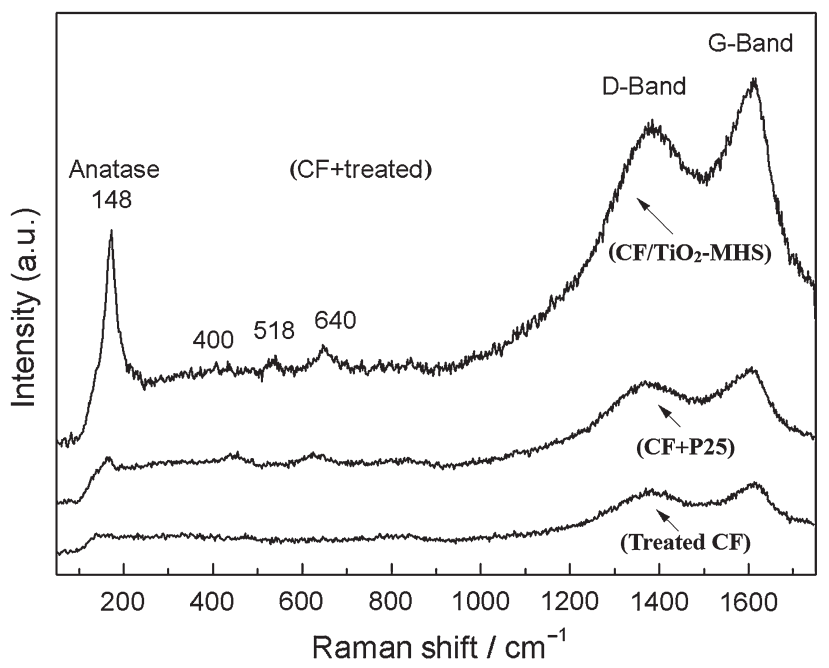

Figure 2. Raman spectrum of $\mathrm{CF}+$ porous.

Table 1. BET data of nanoparticles.

\begin{tabular}{lrc}
\hline Samples & $\mathrm{TiO}_{2}-\mathrm{MHS}$ & $\mathrm{P} 25 \mathrm{TiO}_{2}$ \\
\hline BET surface area $\left(\mathrm{m}^{2} \mathrm{~g}^{-1}\right)$ & 145.15 & 44.968 \\
Total pore volume $\left(\mathrm{cm}^{3} \mathrm{~g}^{-1}\right)^{\mathrm{a}}$ & 0.2689 & 0.0573 \\
Pore diameter $(\mathrm{nm})^{\mathrm{b}}$ & 7.4112 & 5.1012 \\
\hline
\end{tabular}

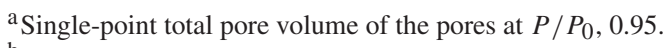

${ }^{\mathrm{b}} \mathrm{BJH}$ desorption average pore diameter.

and the graphitic nature of carbon $\left(\mathrm{sp}^{2}\right)$ on the fibre carbon composite remained the same even after they were impregnated with $\mathrm{TiO}_{2}[14,15]$. In addition, these results show that the material transformed into crystalline anatase $\mathrm{TiO}_{2}$ after microwave treatment was performed; such data is in agreement with the XRD results presented in the previous section.

Table 1 shows the characteristics of pore-size distributions among the nanoparticles of $\mathrm{TiO}_{2}-\mathrm{MHS}$ and conventional P25 
$\mathrm{TiO}_{2}$ obtained by measuring nitrogen adsorption isotherms. The surface area of $\mathrm{TiO}_{2}-\mathrm{MHS}$ was about $145.15 \mathrm{~m}^{2} \mathrm{~g}^{-1}$, i.e., it had a higher relative value when compared with the literature $\left(44.968 \mathrm{~m}^{2} \mathrm{~g}^{-1}\right)$ [16]. This suggests that $\mathrm{TiO}_{2}-\mathrm{MHS}$ sample had a high internal surface area for adsorption of dyes and it could potentially improve the efficiency of light collection. The volume and pore diameter also increased because of the MHS method.

Figure 3 shows FESEM images of samples prepared via different impregnating routes. As shown in figure $3 a$ and $b$, the nanoparticles were uniformly distributed in the $\mathrm{CF}+\mathrm{P} 25$ sample, but a small amount of $\mathrm{TiO}_{2}$ can be seen on the surface when compared with images of the $\mathrm{CF}$ and $\mathrm{TiO}_{2}$-MHS sample in figure $3 \mathrm{c}$ and $\mathrm{d}$. This can be explained by the fact that carbon materials are good microwave absorbers [17,18], and microwave heating can be successfully achieved when carbon materials are used as the microwave receptors in applications such as enhancement of carbon-catalysed reactions [18]. As these materials have high thermal conductivity and can convert radiation energy to thermal energy, the heat created is instantaneously transmitted to the reactants. In the present study, the carbon fibre absorbs microwave radiation and converts it to thermal energy, which is transmitted from the centre to the surface. Then, a preferential zone of synthesis is created on the surfaces of the carbon fibre. This explains the enhanced integration of the $\mathrm{TiO}_{2}$ particles onto carbon fibre when MHS is employed.
It has also been reported that the particle size of clusters vary depending on the solvent and the power of the microwave [19].

The optical band gap ( $E_{\text {gap }}$ ) of the $\mathrm{TiO}_{2}$ samples was calculated following a method suggested in the literature [20]. The values obtained were 3.10 and $3.23 \mathrm{eV}$ for conventional $\mathrm{P} 25 \mathrm{TiO}_{2}$ and $\mathrm{TiO}_{2}-\mathrm{MHS}$, respectively. Previous studies have reported $E_{\text {gap }}$ values of 3.2 and $3.0 \mathrm{eV}$ for the anatase phase [19-23]. Therefore, the result of $3.23 \mathrm{eV}$ is consistent with values reported in the literatures for the anatase phase and the XRD and Raman scattering analysis support it. The result of $3.10 \mathrm{eV}$ for conventional $\mathrm{P} 25 \mathrm{TiO}_{2}$ is also comparable with previously reported values between 3.1 and $3.15 \mathrm{eV}$ for this material $[24,25]$.

\subsection{Photodegradation test, a comparative surface evaluation}

The photodegradation activity of the CF nanocomposites was carried out during the RhB-removal process, and the results are shown in figure 4 and table 2. Under UV irradiation (figure 4a), the $\mathrm{RhB}$ removal rates for $\mathrm{CF}$ and $\mathrm{TiO}_{2}-\mathrm{MHS}$ showed a higher photocatalytic efficiency for the degradation of aromatic pollutants when compared to $\mathrm{CF}+\mathrm{P} 25$ in similar condition, as well as samples under dark conditions. Other authors reported the lowest photocatalytic activity on pure CF substrate as well [26]. In addition, the results
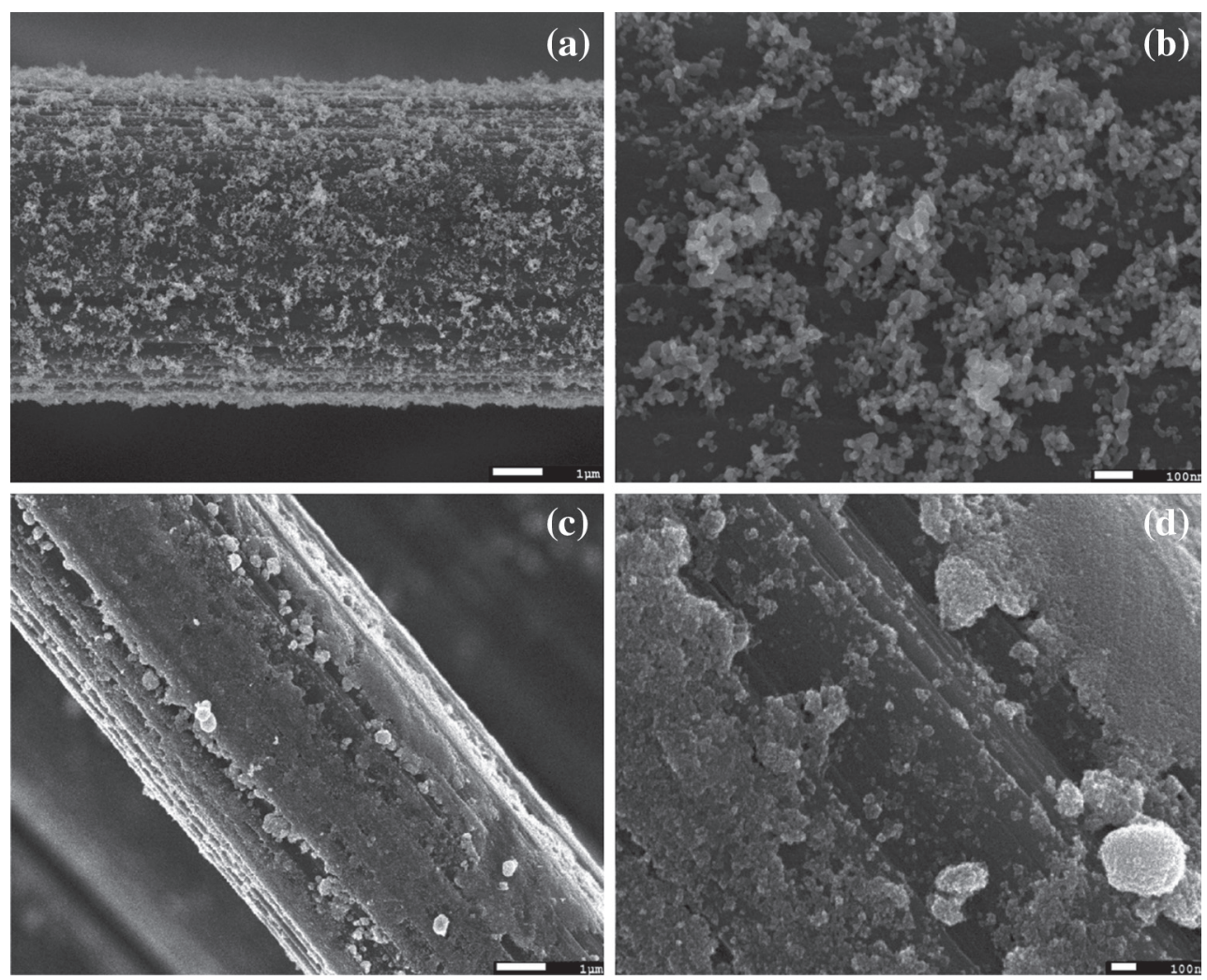

Figure 3. FESEM images of carbon fibre coated with $\mathrm{TiO}_{2}$ : (a) $\mathrm{CF}+\mathrm{P} 25 \times 10,000$, (b) $\mathrm{CF}+\mathrm{P} 25$ $\times 50,000,(\mathbf{c}) \mathrm{CF}+$ Porous $\times 10,000$ and $(\mathbf{d}) \mathrm{CF}+$ Porous $\times 50,000$. 

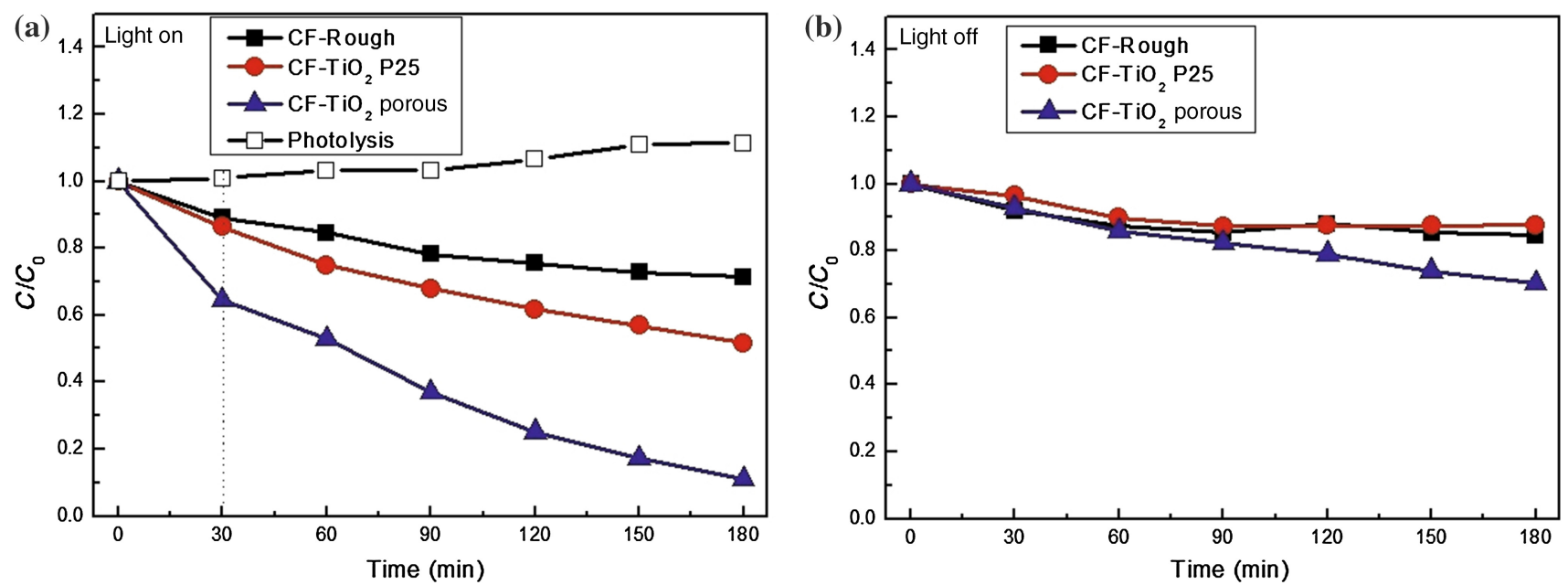

Figure 4. Photodegradation analysis of $\mathrm{RhB}$ on roughness $\mathrm{CF}, \mathrm{CF}+\mathrm{P} 25$ and $\mathrm{CF}+$ porous in the (a) presence and (b) absence of $\mathrm{UV}$ illumination.

Table 2. Comparison of RhB removal rates with and without UV illumination at $180 \mathrm{~min}$.

\begin{tabular}{lccc}
\hline Phenomenon (\%) & Treated CF & $\mathrm{CF}+\mathrm{P} 25$ & $\mathrm{CF}^{2}$ and $\mathrm{TiO}_{2}-\mathrm{MHS}$ \\
\hline Absorption & 19.4 & 12.3 & 29.8 \\
Absorption + photocatalysis & 28.6 & 48.3 & 98.9 \\
\hline
\end{tabular}

suggest that the nanocomposites acted in the separation of $\mathrm{RhB}$ under dark conditions due to minor contribution of adsorption from treated $\mathrm{CF}$ substrate and $\mathrm{TiO}_{2}-\mathrm{MHS}$ particles capacity. Photolysis action was not observed. The curve of adsorption obtained under dark conditions (figure $4 \mathrm{~b}$ ) shows that the $\mathrm{CF}$ and $\mathrm{TiO}_{2}-\mathrm{MHS}$ sample reached saturated adsorptive capacity of $\mathrm{RhB}$ at $\sim 30 \%$.

In general, the ideal photodecomposition conditions the higher aspect ratio between the particle size and surface area, resulting in a small band gap and low electron-hole recombination rate. In these cases, the photodegradation rates of $\mathrm{RhB}$ were higher for the $\mathrm{CF}$ and $\mathrm{TiO}_{2}-\mathrm{MHS}$ sample than the $\mathrm{CF}+$ P25 sample. In fact, a lower optimized $E_{\text {gap }}$ should decrease the recombination rate. On the other hand, here we have two mutual factors: the capacity of the samples to generate - $\mathrm{OH}$ radicals for the degradation process (which was directly related with $\left.E_{\text {gap }}\right)$ and the difference between the available surface area of $\mathrm{TiO}_{2}-\mathrm{MHS}$ and conventional $\mathrm{P} 25 \mathrm{TiO}_{2}$. The result observed here suggests that assembly $\mathrm{TiO}_{2}$, on flexible substrate by MHS, could lead to significant surface performance resulting in higher $\mathrm{RhB}$ photodecomposition rates.

\section{Conclusion}

A versatile semiconductor coating on carbon fibre and $\mathrm{TiO}_{2}-$ MHS was successfully synthesized via MHS. This method offers fast, clean, cost-effective and energy-efficient synthesis, producing a homogeneous layer of $\mathrm{TiO}_{2}$ with controlled thickness. In addition, the procedure proposed allows the growth of different materials, such as PZT. $\mathrm{TiO}_{2}$ nanoparticles prepared via MHS exhibited spherical shapes and abundant pores. The evaluation of nanoparticles attached in the carbon fibre surface was observed by dye photodegradation performance and it suggests a significant particles and fibre carbon interaction as a function of coating via MHS. The successful synthesis was a result of the microwave irradiation, which differs from other heating techniques because of its high penetration allowing it to rapidly heat the bulk material. Combining the advantages of both $\mathrm{CF}$ and $\mathrm{TiO}_{2}$ nanoparticles, the nanocomposite with flexible features can be applied in several areas, like sensors, photovoltaic devices, catalyst support and reinforced material.

\section{Acknowledgements}

The authors gratefully acknowledge (CNPq), for their support in the successful achievement of the project 482251/20131 , as well the (CAPES/PROCAD) under project number 2013/2998/2014 and they also acknowledge (FAPERGS) for their support in completing the project PQG 2013 0020492551/13-2-1. 


\section{References}

[1] De Miguel S R, Vilella J I, Jablonski E L, Scelza O A, SalinasMartinez de Lecea C and Linares-Solano A 2002 Appl. Catal. A Gen. 232237

[2] Nohara L B, Filhob G P, Noharac E L, Kleinked M U and Rezende M C 2005 Carbon 8281

[3] Liu M, Xue D and Li K 2008 J. Alloys Compd. 44928

[4] Ortiz-Landeros J, Gómez-Yáñez C, López-Juárez R, DávalosVelasco I and Pfeiffer H 2012 J. Adv. Ceram. 1204

[5] Yu J and Liu X 2007 Mater. Lett. 61355

[6] Zhan J, Liu D, Du W, Wang Z, Wang P, Cheng H et al $2011 \mathrm{~J}$. Cryst. Growth 3181121

[7] Wang H E, Zheng L X, Liu C P, Liu Y K, Luan C Y, Cheng H, Li Y Y, Martinu L, Zapien J A and Bello I 2011 J. Phys. Chem. C 11510419

[8] Teng F, Zhang G and Wang Y 2015 J. Mater. Sci. 502921

[9] Liang C, Xia W, Soltani-Ahmadi H, Schluter O, Fischer R A and Muhle M 2005 Chem. Commun. 2282

[10] Zhang W F, He Y L, Zhang M S, Yin Z and Chen Q $2000 \mathrm{~J}$. Phys. D Appl. Phys. 33912

[11] Xiang Q, Yu J and Jaroniec M 2012 J. Am. Chem. Soc. 134 6575

[12] Matthews M, Pimenta M, Dresselhaus G, Dresselhaus M and Endo M 1999 Phys. Rev. B 59 R6585
[13] Angoni K 1998 J. Mater. Sci. 333693

[14] Fujishima A, Zhang X and Tryk Da A 2008 Surf. Sci. Rep. 63 515

[15] Ismail A A and Bahnemann D W 2014 Sol. Energy Mater. Sol. Cells $\mathbf{1 2 8} 85$

[16] Wang C, Liu H, Liu Y, He G and Jiang C 2014 Appl. Surf. Sci. 3192

[17] Huang X 2009 Materials (Basel) 22369

[18] Menéndez J A, Arenillas A, Fidalgo B, Fernández Y, Zubizarreta L, Calvo E G et al 2010 Fuel Process. Technol. 911

[19] Periyat P, Leyland N, McCormack D E, Colreavy J, Corr D and Pillai S C 2010 J. Mater. Chem. 203650

[20] López R and Gómez R 2012 J. Sol-Gel Sci. Technol. 611

[21] Pelaez M, Nolan N T, Pillai S C, Seery M K, Falaras P and Kontos A G et al 2012 Appl. Catal. B Environ. 125331

[22] Chen X and Mao S S 2007 Chem. Rev. 1072891

[23] Gaya U I and Abdullah A H 2008 J. Photochem. Photobiol. C Photochem. Rev. 91

[24] Nagaveni K, Hegde M S, Ravishankar N, Subbanna G N and Madras G 2004 Langmuir 202900

[25] Trejo-Tzab R, Alvarado-Gil J J and Quintana P 2011 Top. Catal. $\mathbf{5 4} 250$

[26] Jo W-K, Lee J and Chun H-H 2014 Materials (Basel) 7 1801 